\title{
The effects of food deprivation and the time of the test on muricide in the Long-Evans rat
}

\author{
B. MICHAEL THORNE and BRIAN HUTTON \\ Mississippi State University, Drawer PF, Mississippi State, Mississippi 39762
}

\begin{abstract}
An experiment was performed to determine the effects of food deprivation and the portion of the light-dark cycle in which testing occurred upon the mouse-killing response of the rat. Food deprivation resulted in a significant increase in muricide, while time of the test was not related to the outcome.
\end{abstract}

Many studies of the rat's mouse-killing response have been performed since the seminal report by Karli (1956). Some of the variables known to affect the response are food deprivation (e.g., Malick, 1975; Paul, Miley, \& Baenninger, 1971; Rager \& Thorne, 1977), type of mouse employed in the test (Thorne \& Thompson, 1976), and brain damage (e.g., Malick, 1970; Thorne, Aaron, \& Latham, 1973, 1974). One variable that has not been investigated to our knowledge is that of the time of the test.

Muricidal tests are typically initiated during the light portion of the rat's light-dark cycle. It is well known that rats, like other nocturnal animals, do most of their feeding during the dark portion of the cycle. Since hunger and muricide are related (e.g., many studies have shown that food deprivation results in increased muricide), it is possible that a higher percentage of rats tested during the dark portion of the cycle would kill than rats tested in the light portion. The present experiment was designed to investigate this possibility. In addition, some animals were food deprived prior to testing to see if the effects of food deprivation would interact with the time of testing.

\section{METHOD}

\begin{abstract}
Subjects
The subjects were 40 adult Long-Evans hooded rats, half male and half female, divided into four groups of 10 subjects each. All animals were singly housed and were kept in a large colony room on an 8-h on/16-h off light-dark cycle. Half of the animals were placed on a food-deprivation schedule in which each rat received approximately $7.5 \mathrm{~g}$ of rat chow daily. Feeding occurred approximately $1-2 \mathrm{~h}$ into either the light or dark portion of the cycle, depending upon whether the animal was going to be tested in the light or in the dark. Muricidal testing during the dark portion of the cycle was conducted with the illumination from a dim red bulb, and all animals were allowed to adapt to the feeding regimen and light-dark cycle for at least 1 week prior to testing.
\end{abstract}

This research was in part supported by an institutional grant from the National Science Foundation awarded to Mississippi State University. Requests for reprints should be sent to B. Michael Thorne, P. O. Drawer PF, Mississippi State, Mississippi 39762.

\section{Procedure}

Each animal was given a muricidal test at the time feeding normally occurred (i.e., at approximately $1-2 \mathrm{~h}$ into the appropriate portion of the light-dark cycle). The test consisted of placing an adult albino mouse into the cage of each rat. The length of the test was $30 \mathrm{~min}$, with continual observation throughout. At the end of the test, any live mice and the remains of any dead mice were removed from the cages. Latency to kill was recorded where appropriate.

\section{RESULTS AND DISCUSSION}

Since males and females did not differ in rate of killing, their data were combined for all further tests. The time of the test, that is, whether it was conducted in the light or the dark portion of the light-dark cycle, did not significantly affect the rate of killing. In fact, in contrast to the predicted outcome, slightly more rats killed in the day test (35\% vs. $20 \%$ for all groups combined). A comparison of latency scores for night killers and day killers was not significant.

As expected, food deprivation resulted in a significant increase in the rate of killing when results of the day-night tests were combined $\left(\chi^{2}=5.83\right.$, corrected for continuity, $\mathrm{p}<.05)$. This result also held for tests conducted at night $(p=.043$, Fisher's exact probability test) and for tests during the light portion of the cycle $(\mathrm{p}=.0302)$.

Thus, the present experiment reemphasized the belief that food deprivation results in an increase in mouse killing in the rat. Despite the evidence that hunger and muricide are related and the fact that rats feed more at night, we found no evidence for an increased probability of muricide in tests conducted during the dark portion of a light-dark cycle.

\section{REFERENCES}

KARLI, P. The Norway rat's killing response to the white mouse: An experimental analysis. Behaviour, 1956, 10, 81-103.

MALICK, J. B. A behavioral comparison of three lesion-induced models of aggression in the rat. Physiology and Behavior, 1970, 5, 679-681.

Malick, J. B. Effects of age and food deprivation on the development of muricidal behavior in rats. Physiology and Behavior, 1975, 14, 171-175. 
Paul, L., Miley, W. M., \& Baenninger, R. Mouse killing by rats: Roles of hunger and thirst in its initiation and maintenance. Journal of Comparative and Physiological Psychology, 1971, 76, 242-249.

RAGER, K. B., \& ThORNE, B. M. The effects of food deprivation and the length of the test on muricide in rats. Physiology and Behavior, 1977, 18, 759-762.

Thorne, B. M., Aaron, M., \& Latham, E. E. Effects of olfactory bulb ablation upon emotionality and muricidal behavior in four rat strains. Journal of Comparative and Physiological Psychology, 1973, 84, 339-344.
Thorne, B. M., Aaron, M., \& Latham, E. E. Olfactory system damage in rats and emotional, muricidal, and rat pup killing behavior. Physiological Psychology, 1974, 2, 157-163.

Thorne, B. M., \& Thompson, M. E. The effect of different types of mice upon muricidal behavior in the Long-Evans rat. Physiological Psychology, 1976, 4, 238-246.

(Received for publication January 28, 1978.) 